\title{
Kinetic Study of the Effect of Plasticization on Photodegradation of Polystyrene Solid Films
}

\author{
Khalid E. Al Ani1 ${ }^{*}$, Afrah Essa Ramadhan² \\ ${ }^{1}$ Department of Pharmaceutical Chemistry, Faculty of Pharmacy, Jadara University, Irbid, Jordan \\ ${ }^{2}$ Department of Industrial Chemistry, Institute of Technology, Baghdad, Iraq \\ Email: ${ }^{*}$ khalidalani44@yahoo.com
}

Received 30 May 2015; accepted 5 July 2015; published 8 July 2015

Copyright (C) 2015 by authors and Scientific Research Publishing Inc.

This work is licensed under the Creative Commons Attribution International License (CC BY). http://creativecommons.org/licenses/by/4.0/

\section{Open Access}

\section{Abstract}

The effects of UV-irradiation on stability of pure and blended polystyrene films with phthalate and terephthalate plasticizers were studied in presence of air. UV-visible, fluorescence and FT-IR techniques were used to study the photodegradation of irradiated polystyrene films. Increase of irradiation times of polystyrene films caused an increase in the intensity of the main absorption band and the increase in the intensity of a new absorption band at longer wavelength, thus indicating a possibility of photo degradation of polystyrene chains. The influence of added plasticizers, dimethyl terephthalate, diethyl terephthalate, dioctyl terephthalate, dioctylphthalate, and dibutyl phthalate on photo-quenching of the polymer fluorescence band was also investigated, and found to increase the photodegradation processes in polymeric chains. On the other hand, the intensity of excimer and monomer fluorescence bands maxima was also found to decrease with a small red shift with the increase in irradiation times. These changes may be attributed to the formation of new photo-products resulted from the photodegradation of irradiated polymeric chains. The photo-quenching rate constant was found to increase with the increase of the molar mass and bulkiness of the used plasticizers and to increase with the increase in irradiation time. The rate constant of the photo quenching process was found to decrease with the increase in the percent of added plasticizers, indicating that the added plasticizers might act as UV-absorbers which inhibited the photodegradation process. The analysis of the FT-IR spectra of the irradiated and nonirradiated samples showed a noticeable formation of new broad band centered at $1727 \mathrm{~cm}^{-1}$, and its intensity was found to increase with the increase in irradiation time and also with the increase in the amount of added plasticizer. In addition, the observed increase in the intensities of the carbonyl and hydroxyl absorption regions of the FT-IR spectra provided evidence for the photodegradation as well as photo-oxidation of polymeric chains.

\footnotetext{
Corresponding author.
} 
Keywords

Excimer Fluorescence, Photodegradation Kinetics, Phthalateplasticizers, Polystyrene

\section{Introduction}

Polystyrene (PS) is a very important polymer that has many excellent properties, such as high electrical resistance, and good mechanical properties under various conditions. However, since PS degrades easily upon exposure to light energy, several mechanisms are proposed to explain the photodegradation steps in polymeric chains [1]-[4]. The photodegradation of polymeric chromophores is always initiated by absorption of light with enough energy that leads to formation of highly reactive chemical species in the polymer backbones. Free radicals are one of the species more frequently produced under these conditions. Free radicals are capable of reacting with oxygen and producing a series of chemical reactions, which lead to chain scissions and cross linking in the polymeric materials [5]-[7]. Lawrence and Weir [8] have observed two types of chain scissions in PS solution at wavelength $(\lambda>300 \mathrm{~nm})$. The first type is a pure photo process which occurs completely independently of oxygen, and the second type is a process associated with random photolysis of the products of oxidation. They also have discussed the nature of the photo labile bond, as there is some evidence for a peroxide linkage arising from oxygen copolymerization in polymer chains. They also have suggested that fission of the photo labile groups contributes to the initiation of the long-wavelength photo-oxidation of the polymer chains [8].

It has been also suggested that the photo-oxidation processes in PS films involve two possible mechanisms: the first is the photoreaction that is based on the dissociation of excited peroxide macro radicals, leading to the formation of $\mathrm{H}_{2} \mathrm{O}$ and $\mathrm{CO}_{2}$; the second mechanism is hydroperoxides' mechanism which is converted to form the radicals in initiation stage including an $\mathrm{RO}_{2}^{*}$ radical reaction with the polymer chromophore which produces hydroperoxides. A subsequent $\mathrm{ROOH}$ decomposition results in the scission of the polymer chains and formation of high-molecular oxidation products such as carbonyl, alcohols, and ethers [7] [9].

The UV-photodegradation of PS films has been studied using fluorescence spectroscopy [10]. Excitation and dispersed fluorescence spectra were also collected as a function of time of exposure to broad-band $(\lambda>300 \mathrm{~nm})$, to monitor the chemical changes in the films. The fluorescence excitation and the dispersed fluorescence spectra gave direct evidence that degradation products indicated to conjugated double bond along the polystyrene backbone named polyene structures- $\left(\mathrm{C}_{(}\left(\mathrm{C}_{6} \mathrm{H}_{5}\right)=\mathrm{CH}\right)_{\mathrm{n}}$. Polyenestructure is responsible for color change of PS under UV-exposure [10] [11]. On the other hand, polymeric additives were found to accelerate the radiation-induced degradation of polystyrene and substituted polystyrene films [12] [13]. It was reported that the photo-stability of PS was reduced by the addition of bromine containing flame retardant, and appeared to depend upon the chemical structure of the polymeric additives [12]. For PS containing carbonyl group, it was found that the photodegradation increased with increasing in irradiation time. The changes in the average molecular weight in photooxidized PS were produced as consequences of chain dissociation by Norrish Type II reaction [13].

It was also reported that the photo-stability of substituted polystyrene (SPS) was reduced by blending with phthalate and terephthalat plasticizers. Phthalate plasticizers were more efficient in the increase in the photodegradation of irradiated polymeric chromophores in solid films [14]-[18]. The photodegradation of thin films of poly(p-tert-butylstyrene) with $254 \mathrm{~nm}$ radiation, under high vacuum, has been studied. The main evolve gas is hydrogen; little amount of methane, ethane, and isobutene are also formed, indicating that fission of bonds in the tert-butyl group has occurred [15]. On the other hand, the photodegradation of thin films poly( $p$-fluorostyrene), poly ( $p$-chlorostyrene) and poly( $p$-bromostyrene) has been studied, by exposure to $254 \mathrm{~nm}$ radiation, and under high vacuum. The irradiated polymers showed a yellowish discoloration caused by irradiation; this was related to the formation of chain double bonds as a result of hydrogen atom abstraction from the $\mathrm{C}$-atom in $\gamma$ position of the phenyl group [18] [19].

In the present work, the photodegradation of irradiated polystyrene films, and the effects of blending with phthalate and terephthalate plasticizers on the photo-stability were also investigated with the following aims:

1) To compare the photo-stability of pure and blended polystyrene films with phthalate and terephthalate plasticizers, with that of other substitutes polystyrenes in solid films;

2) To study the effect of blending PS films with phthalate and terephthalate plasticizers on its photo-stability, 
and to select the best polymeric additive that could cause less photodegradation on the irradiated polymeric films;

3) To apply Al Ani-Hawi relation [17], in order to evaluate some kinetic parameters such as photo quenching rate constant, and quenching efficiencies of irradiated pure and blended polymer films.

The photodegradation processes of the exposed polymer films for different intervals of time have been characterized by UV-visible, fluorescence and FT-IR spectroscopic techniques. The efficiency of photodegradation of pure film is compared with that of blended polymer films.

\section{Materials and Methods}

\subsection{Materials}

The sample of polystyrene (PS) was supplied by Aldrich Chem. Co., with $(\mathrm{Mw}=212,400)$ and was used without further purifications. Only spectroscopic grade dichloroethane (DCE) was used in casting of solid films, and was found to give no detectable absorption in range $(250-400 \mathrm{~nm})$. It was purchased from Fluka GMBH and was used as received. The used plasticizers are dimethyl terephthalate (DMT), diethyl terephthalate (DET), dioctyl terephthalate (DOT), dibutyl phthalate (DBP) and dioctyl phthalate (DOP). These were of high purity of about $(99.8 \%)$, and were purchased from Across-Organics and were used without further purifications.

\subsection{Preparation of Plasticized Polymeric Solid Films}

PS thin films with thickness of approximately $0.02 \mathrm{~mm}$ were prepared by solution casting of $20 \mathrm{wt} \%$ polymer in DCE on a spectroscopic window (quartz plate of $1.0 \mathrm{~mm} \times 20 \mathrm{~mm}$ diameter). Moreover, about $0.02 \mathrm{~mm}$ thick PS-plasticizer films, containing different $\mathrm{wt} \%$ plasticizers were prepared by solution casting of $20 \mathrm{wt} \%$ polymer + added plasticizer, in DCE solvent. These films were used as to gain better insight into the possibility of photodegradation of the polymer during irradiation. The films were dried in a vacuum oven at $293 \mathrm{~K}$ for 6 hours, as to ensure the complete removal of solvent traces [20].

\subsection{Absorption, Fluorescence and FT-IR Spectra Measurements}

The UV absorption spectra for PS solid films were recorded before and immediately after UV irradiation with a Cary 100 Bio UV-visible Spectrophotometer at $298 \mathrm{~K}$.

Fluorescence spectra were recorded on JASCO-FP 6500 Spectrofluorometer for each of the prepared samples. The parameters were constant for all measurements, and the excitation wavelength was $265 \mathrm{~nm}$. The emission wavelength range was $(270-500 \mathrm{~nm})$, and all fluorescence spectra for the solid films were obtained using a thermostated solid sample holder.

Polystyrene solid films were exposed to different intervals of irradiation time in air, from (0.0 - 4.0 hours), using a JASCO-Spectrofluorometer with a built in Hydrogen-Xenon lamp (6808-J007A model number ESC333 ), and supported with monochromator of holographic grating with 1800 groves $/ \mathrm{mm}$. The intensity of incident radiation was $\left(4.9 \mathrm{~mW} / \mathrm{cm}^{2}\right)$, and the distance between light source and samples was $(5 \mathrm{~cm})$. All films were exposed to the same rate of irradiation intensity.

The Fourier transform infrared spectroscopy (FT-IR) system that was employed in this work was NICOLETMAGNA-IR-560 Spectrometer, while the transmission mode was employed in these measurements. The working wavenumber range of the spectrometer was from $\left(4000\right.$ to $\left.500 \mathrm{~cm}^{-1}\right)$, with a resolution of $\left(4 \mathrm{~cm}^{-1}\right)$. The FT-IR spectra were recorded immediately for the irradiated and the non-irradiated films, whereas the transmittance was plotted as function of the wavenumber.

\section{Results and Discussion}

\subsection{Irradiation Effect on Absorption Spectra of Pure and Blended Polystyrene Films}

The absorption spectra of irradiated polystyrene at 0.0, 2.0 and 4.0 hours are shown in Figure 1(A) and Figure 1(B) shows the irradiated polystyrene film blended with $4.0 \%$ of dioctyl terephthalate (DOT).

As can be seen from Figure 1(A) and Figure 1(B), irradiation of PS and blended PS films with 4.0\% DOT resulted in a small increase in the absorption intensity of the main absorption bands with a small change in the 


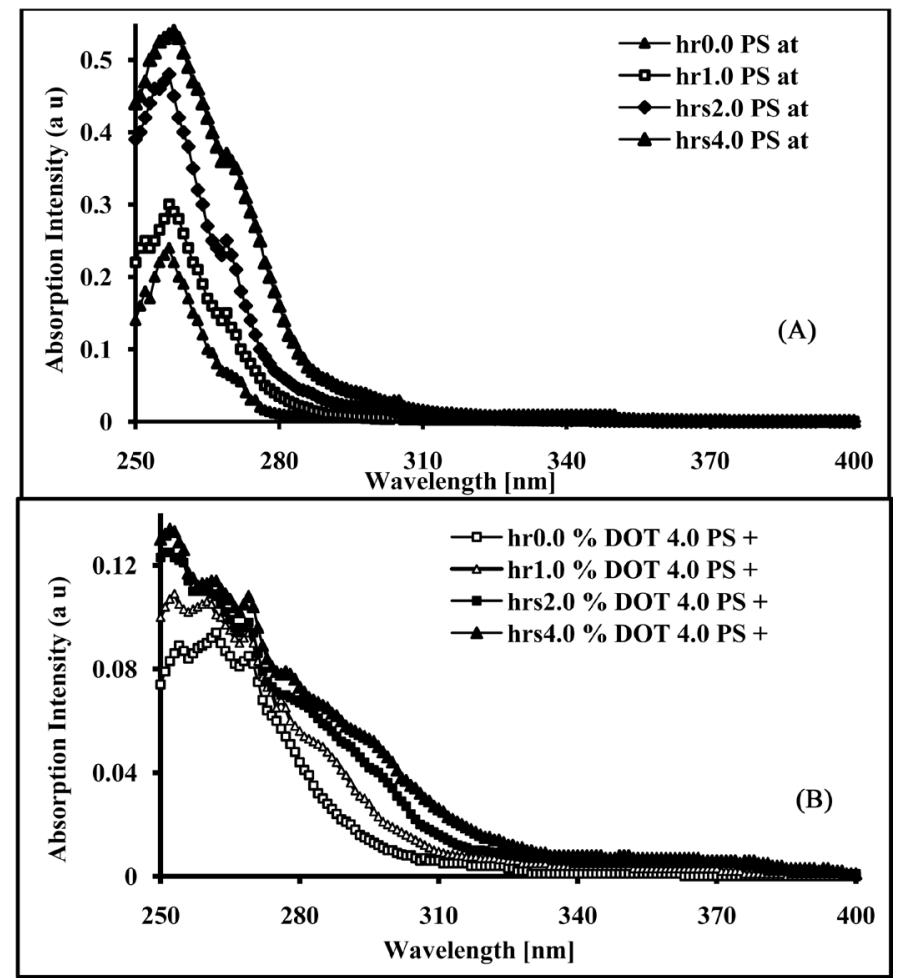

Figure 1. UV-absorption spectra of irradiated solid films for $0,1,2$, and 4 hoursof: (A) PS and (B) PS blended with $4.0 \%$ dioctyl terephthalate $\left(\lambda_{\text {ext }}=265 \mathrm{~nm}\right)$.

shape of the absorption spectra. We also noticed a small increase in the absorption intensity of a new broad band with no clear maxima at longer wavelength at $\lambda=(280-330 \mathrm{~nm})$. The intensity of absorption spectra increased by the increase in UV-aerated exposure time, and also increased upon blending with dioctyl terephthalate plasticizer. The change in the shape of the absorption spectra may be attributed to the formation of low molecular mass products that can be formed as a result of the reaction between radicals through abstracting hydrogen atoms from the polymer chromophores in irradiated PS films. It is well known that the changes in the absorption spectra, which associated with the increase in the exposure time of irradiation, are much more effective when irradiations are carried out in the presence of air. Oxygen molecules play an important part in accelerating the degradation of polymer backbone through the photo-oxidation processes. The presence of oxygen may initiate peroxy-radicals that can accelerate the photogegradation of polymeric chains [7]. The new formed fragments absorb at longer wavelength and that caused the formation of a broad absorption band at longer wavelength. The presence of plasticizer molecules in the irradiated polymer backbone may also enhance the absorption intensity of the formed broad band, and possibly, by accelerates the photochemical processes in polymeric chains. This suggests that added plasticizers alter both the photochemical stability of PS, and the process which lead to the increase of absorption, such as photodegradation (with scission of bonds in the polymer chains) or photo transformation (with changes in the conformation of plasticizer molecules) [12], and was found to increase in the molar mass of the added plasticizer. Moreover, the increase in the intensity of the absorption broad band at longer wavelength; may suggest that photo-oxidation and photodegradation processes are the main dominating processes in the irradiated pure and blended polymer films, may be attributed to the formation of the $\mathrm{C}=\mathrm{C}$ bonds in combination with carbonyl groups, in the polymer backbone [13].

\subsection{Effect of UV-Irradiation Time on Intensity of Fluorescence Spectra of Pure and Blended PS Films with DMT, DET, DOT, DBP and DOP Plasticizers}

A number of studies have provided information about photodegradation of polystyrene films, but none of these studies have dealt with the photodegradation of blended PS with phthalate and terephthalate plasticizers in solid 
films. Therefore, the effect of irradiated light energy on the degradation of pure and blended PS films has been studied as function of the increase in irradiation times, by recording their fluorescence spectra before and after irradiation for different intervals of time.

The fluorescence spectra for the irradiated solid film of PS films, showed a gradual decrease in their emission intensities with the increase in irradiation times. The fluorescence spectra for PS film showed a very weak monomer fluorescence band and a strong excimer fluorescence band at longer wavelength [21]. The excimer fluorescence band is centered at about, $\left(\lambda_{\max }=327 \mathrm{~nm}\right)$, and the monomer fluorescence band is centered at about, $\left(\lambda_{\max }=306 \mathrm{~nm}\right)$. The fluorescence spectra of irradiated pure PS film, and blended PS films with 4.0\% DMT and DET are shown in Figure 2.

Figure 3 shows the fluorescence spectra of irradiated blended PS films with $4.0 \%$ of DBP and DOP.

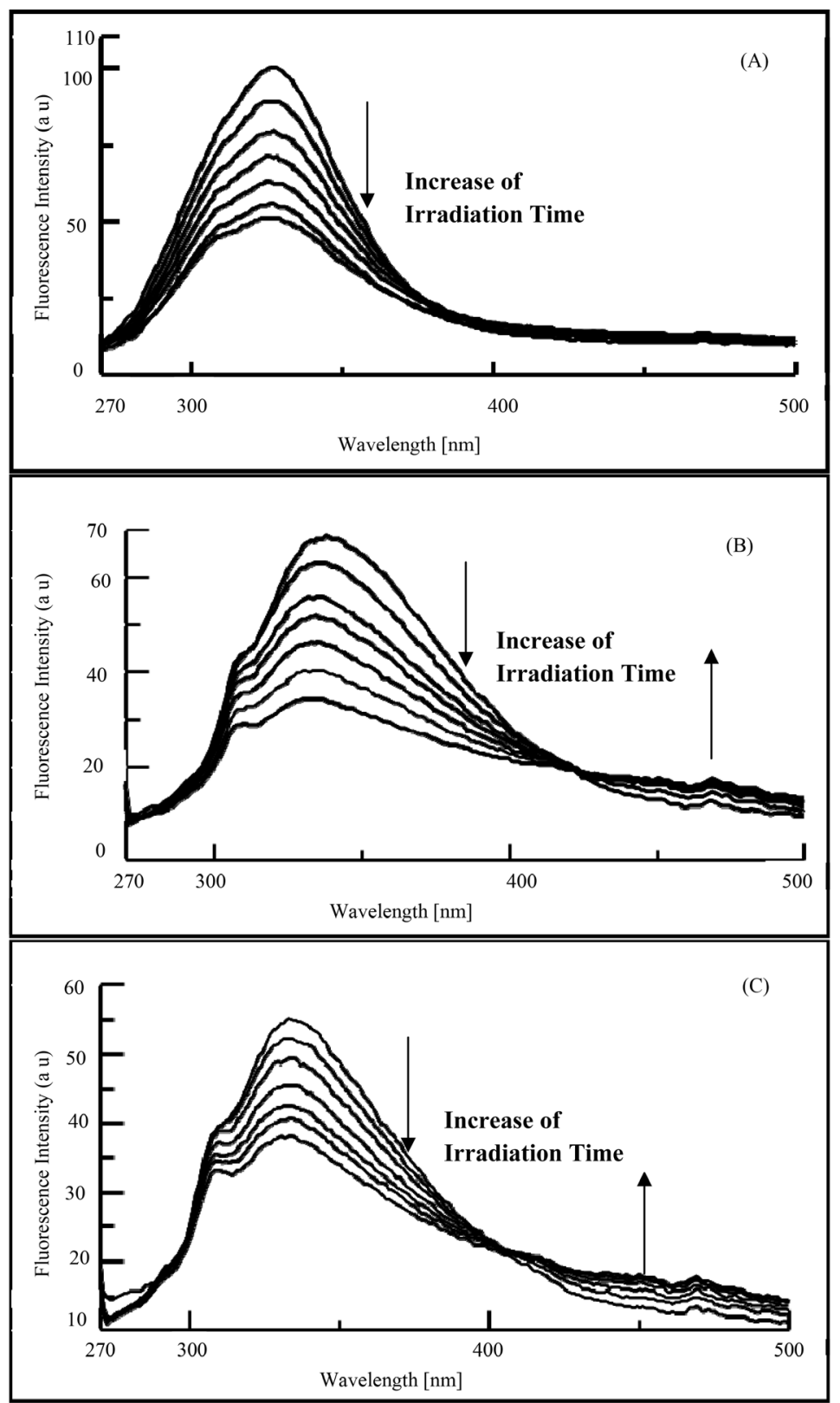

Figure 2. Fluorescence spectra of irradiated solid films of: (A) PS, (B) PS blended with 4.0\% DMT, and (C) PS blended with 4.0\% DET, for 0,10 , $30,60,90,120$ and $180 \mathrm{~min}$., at $\left(\lambda_{\mathrm{ext}}=265 \mathrm{~nm}\right)$. 


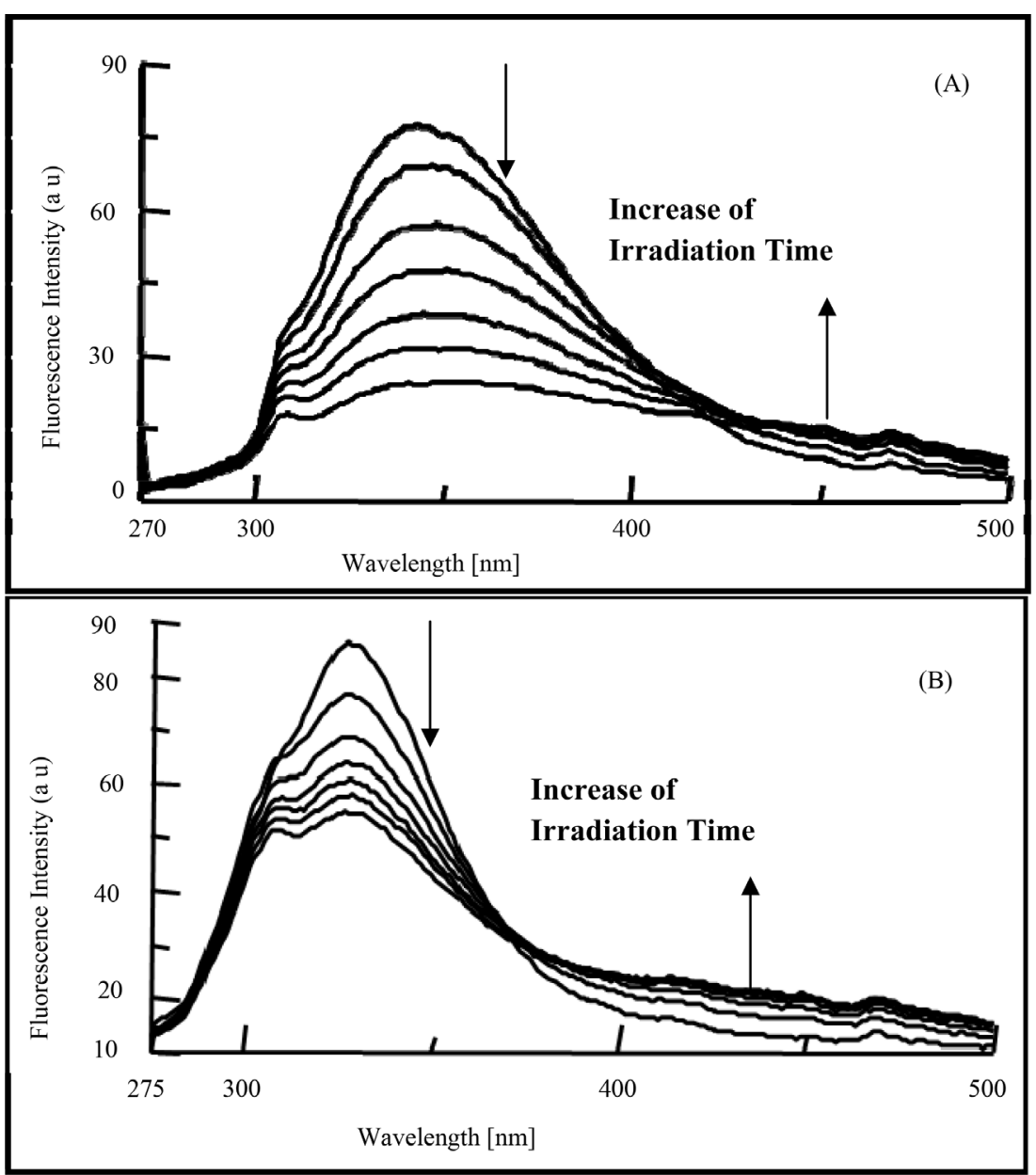

Figure 3. Fluorescencespectra of solid films of irradiated: (A) PS blended with $4.0 \%$ DOP, and (B) PS blended with 4.0\% DBP, for 0, 30, 60, 90, 120, 150 and 180 min., at $\left(\lambda_{\text {ext }}=265 \mathrm{~nm}\right)$.

As can be seen form Figure 2(A)-(C), and Figure 3(A) and Figure 3(B), irradiation of the polymeric films at different exposure time was accompanied by the gradual decrease in the intensity of both monomer and excimer emissions. It seems that the decrease in the intensity of excimer fluorescence occurs as a result of photodegradation of polymeric chains. The shift in the peak position can be explained by the formation of the conjugated double bonds during the photodegradation by hydrogen abstraction process [21]-[24]. Weir et al. have proposed a mechanism by which polystyrene undergoes photolysis with evolution of hydrogen to yield a conjugated diene [21]. In this mechanism, the first photoreaction was initiated by the absorption of light energy that leads to the dissociation of the $(\alpha-\beta)$ hydrogen from the polymer backbone. The dissociated hydrogen atoms can then abstract hydrogen atoms from neighboring $(\beta)$ carbon to form molecular hydrogen and unsaturated bond in polymer backbone. The presence of an excited unsaturated end group can also lead to polyene formation by a hydrogen elimination reaction [21]. These conjugated sequences not only absorb in the UV-region of the visible spectrum, but also fluorescence. The formation of conjugated double bonds along the polymer backbone (polyene structure) creates the new emission band at longer wavelength [10].

Geuskens et al., have studied the photodegradation of polymers and found that the photogegradation of polymeric chains was attributed to the effect of peroxides formed during UV-irradiation [23] [24]. The formation of a broad fluorescence band at wavelength range $(316-400 \mathrm{~nm})$ was resulted from the formation of new photo products that were formed during irradiation of polymeric chains.

It is well known that photo-oxidation of PS chains gave polyene structures, peroxides, ketones and alcohols. Tovborg and Kops, pointed out that the quenching of emission of the polymer might be attributed to the energy 
transportation of the oxides formed by the photo-oxidation during the irradiation of polymeric chromophores [25].

Blending PS films with different percentages of DMT, DET, DOT, DOP and DBP, was accompanied by the quenching of the intensity of excimer fluorescence band and to decrease with the increase the amount of added plasticizers. Irradiation of blended PS films resulted in the formation of new fluorescence band at longer wavelength and to increase its intensity with increase in irradiation times, as shown in Figure 2(B) and Figure 2(C) and Figure 3(A) and Figure 3(B). The formation of the fluorescence broad band with no clear maxima in the irradiated blended PS films is in full agreement with that reported by Geuskens et al., on photo irradiated PS films [23]. The formation of new fluorescence band at $(362,425$ and $477 \mathrm{~nm})$, correspond to the formation of polyene unit structures and defined by $n=1,2$, and 3, respectively, where (n) represents the number of double bands [24]. As seen in Figure 2(B) and Figure 2(C) and Figure 3(A) and Figure 3(B) of blended PS films, although the formation of a new broad band has no clear maxima, with highest intensity lies at $476 \mathrm{~nm}$, this may indicate the possibility of formation of polyene unit structures during the photodegradation of polymeric chains.

An isosebastic point was observed in the photo irradiation of plasticized (PS) films, indicating that the major process is the photodegradation of polymeric chains. The quenching effect of the intensity of exciplex fluorescence was found to increase with the increase of irradiation times and to increase with increase of added amount of plasticizers. As a result of irradiation process, a small red shift was noticed in the $\left(\lambda_{\max }\right)$ of excimer fluorescence of pure and blended PS films, as seen in Table 1.

As can be seen from Table 1, a red shift was noticed upon the irradiation of pure and plasticized PS films. The red shift in the $\left(\lambda_{\max }\right)$ of both excimer and monomer fluorescence bands was increased by the increase in amount of added plasticizer, and by the increase in irradiation times. The intensity of the formed new broad fluorescence band at longer wavelength was increased with the increase in irradiation times, indicating an increase in the degradation efficiency upon the increase in irradiation time.

The effect of change in the molecular structure and molar mass of the doped plasticizers was found to be very effective in the stability of irradiated blended PS solid films. We have noticed that terephthalates as in the case of DMT, DET and DOT, caused less degradation effect in comparison with that observed in phthalates plasticizer like DBP and DOP. On the other hand, the increase in the molar mass on the used plasticizers caused higher efficiency of polymer degradation due to the increasing in bulkiness of plasticizer molecules. Similar results were obtained for irradiation of blended substituted polystyrene [17] [18].

\subsection{Kinetics and Mechanism of Photodegradation of Pure and Blended PS Solid Films}

The effects of blended amount of the added plasticizers and the increase in irradiation time on the fluorescence intensity of PS films were studied as function of increase in irradiation times.

Al Ani and Hawi [15] have formulated a new mathematical relation that can be used to study the kinetic treatments to the fluorescence quenching of PS film by the increase in the amount of added plasticizers and by the increase in irradiation times at room temperature.

If we consider that $\left(I_{E X}^{o}\right)^{*}$ is the intensity of excimer fluorescence of pure or blended polymer at zero time of irradiation, and $\left(I_{E X}\right)^{*}$ is the intensity of excimer emission of pure or blended polymer at different intervals of exposure time. Then, the ratio of $\left(I_{E X}^{o}\right)^{*} /\left(I_{E X}\right)^{*}$ was found to increase by the increase in irradiation time $(t)$

Table 1. Effect of plasticization on the $\left(\lambda_{\max }\right)$ of excimer and monomer fluorescence bands, and the red shift in excimer fluorescence band, at $\left(\lambda_{\mathrm{ext}}=265 \mathrm{~nm}\right)$.

\begin{tabular}{|c|c|c|c|c|c|}
\hline Polymer & $\begin{array}{l}\% \text { Blended } \\
\text { Plasticizer }\end{array}$ & $\begin{array}{l}\lambda_{\max }(\mathrm{nm}) \\
\text { Monomer }\end{array}$ & $\begin{array}{l}\lambda_{\max }(\mathrm{nm}) \\
\text { Excimer }\end{array}$ & $\begin{array}{l}\text { New Fluorescence } \\
\text { Broad Band (nm) }\end{array}$ & $\begin{array}{c}\text { Red Shift after } \\
\text { (Irradiation }-180 \mathrm{~min})(\mathrm{nm})\end{array}$ \\
\hline PS & ------- & 306 & 327 & ------- & 6.0 \\
\hline PS & DMT, $4.0 \%$ & 308 & 334 & $434-508$ & 9.0 \\
\hline PS & DET, $4.0 \%$ & 308 & 336 & $430-510$ & 6.0 \\
\hline PS & DOT, $4.0 \%$ & 313 & 344 & $436-512$ & 11.0 \\
\hline PS & DEP, $4.0 \%$ & 309 & 334 & $372-505$ & 7.0 \\
\hline PS & DOP, $4.0 \%$ & 314 & 432 & $372-505$ & 10.0 \\
\hline
\end{tabular}


of polymeric films, and is given by the following relation:

$$
\left(\frac{I_{E X}^{o}}{I_{E X}}\right)^{*}=1+\left[\left\{\left(k_{P Q}^{\prime}\right)(A)\right\}(t)\right]
$$

where $[A]=$ number of (photons/s) absorbed by polymeric chromophores.

$t=$ time of irradiation in s;

$k_{P Q}^{\prime}=$ rate constant.

If $(\mathrm{A})$ is the number of photons released from the light source and absorbed by polymer chromophores is constant. Then we can write:

$$
k_{P Q}=\left\{\left(k_{P Q}^{\prime}\right)(A)\right\}
$$

where $\left(k_{P Q}\right)$ is the photo-quenching rate constant, and the efficiency of quenching ratio $\left(I_{E X}^{o}\right)^{*} /\left(I_{E X}\right)^{*}$ is given is given by the following equation:

$$
\left(\frac{I_{E X}^{o}}{I_{E X}}\right)^{*}=1+\left[\left(k_{P Q}\right)(t)\right]
$$

According to Equation (3), $\left(I_{E X}^{o}\right)^{*} /\left(I_{E X}\right)^{*}$-values were plotted against time of irradiations (t). From the plots, the photo-quenching rate constant $\left(k_{P Q}\right)$ values and quenching efficiency ratio $\left(\left(I_{E X}^{o}\right)^{*} /\left(I_{E X}\right)^{*}\right)$ ratios were calculated and were used to estimate the efficiency of photodegradation processes for pure and blended polymer. The plots of the ratio of excimer fluorescence $\left(I_{E X}^{o}\right)^{*} /\left(I_{E X}\right)^{*}$ against the different irradiation times (0 - $\left.180 \mathrm{~min}\right)$ of pure and blended PS films with $0.0 \%, 1.0 \%, 2.0 \%, 3.0 \%$ and $4.0 \%$ of DMT, DET and DOT plasticizers are presented in Figure 4, and for DBP and DOP are presented in Figure 5.

It is a common fact that excimer emission of irradiated PS and SPS chromophores is quenched in the presence of ground state plasticizer molecules [20]. The efficiency of quenching was found to depend on the chemical structure of the plasticizer as well as the molar mass of plasticizer molecule. The increase in the irradiation time caused degradation to polymeric chains as well the normal fluorescence quenching process.

Blending of PS solid film with phthalate and terephthalate plasticizers may offer opportunities to improve their properties for industrial uses by reducing the brittleness of plastics. So far, many studies on blends containing poly(vinyl acetate) and PS have been reported [26] [27]. It was found that the processes of photo-oxidation and photodegradation were accelerated in blends compared to pure poly(vinyl acetate), and pure PS [27].

As can be seen from Figure 4 and Figure 5, the decrease in the fluorescence intensity and the increase in the $\left(I_{E X}^{o} / I_{E X}\right)$ ratio with increase in irradiation times, indicates that the irradiation process may be accompanied by photochemical reactions in polymeric chains. Chain scissions and photo-oxidation processes that were interpreted as a reaction involving benzene ring-opening photo-oxidation were the processes that resulted from irradiation of PS in the presence of polymeric additives [27]-[29]. It has been reported that the photostability of polystyrene films was reduced by blending with polymeric additives, as to depend on the chemical structure of the additive [29].

The increase in the $\left(I_{E X}^{o} / I_{E X}\right)$ ratio which represents the ratio of the quenching efficiency is affected by the molecular structure of added plasticizer. The efficiency of photo-quenching for plasticized polymer showed a lower value than that for pure polymer, and was also found to increase with the increase in the bulkiness of plasticizer molecules [30] [31]. Blending with DOT showed the higher value of quenching while blending with DOP gave the lower values of quenching with increase in irradiation times. The efficiency of photodegradation of blended PS with 4.0\% DMT, DET, DOT, DBP and DOP is shown in Figure 6.

In an earlier work, it was reported that the photo-stability of para-substituted polystyrene, was reduced by the addition of polymeric additives and to depend on the chemical structure of the para-substituted group and also on the bulkiness of the plasticizer molecules [15]-[18].

As can be seen from Figure 6, the trend of increase in the efficiency of excimer fluorescence quenching is DOT $>$ DMT $>$ DBP $>$ DET $>$ DOP. This trend is explained by assuming that the [PS-terephthalate] energy 


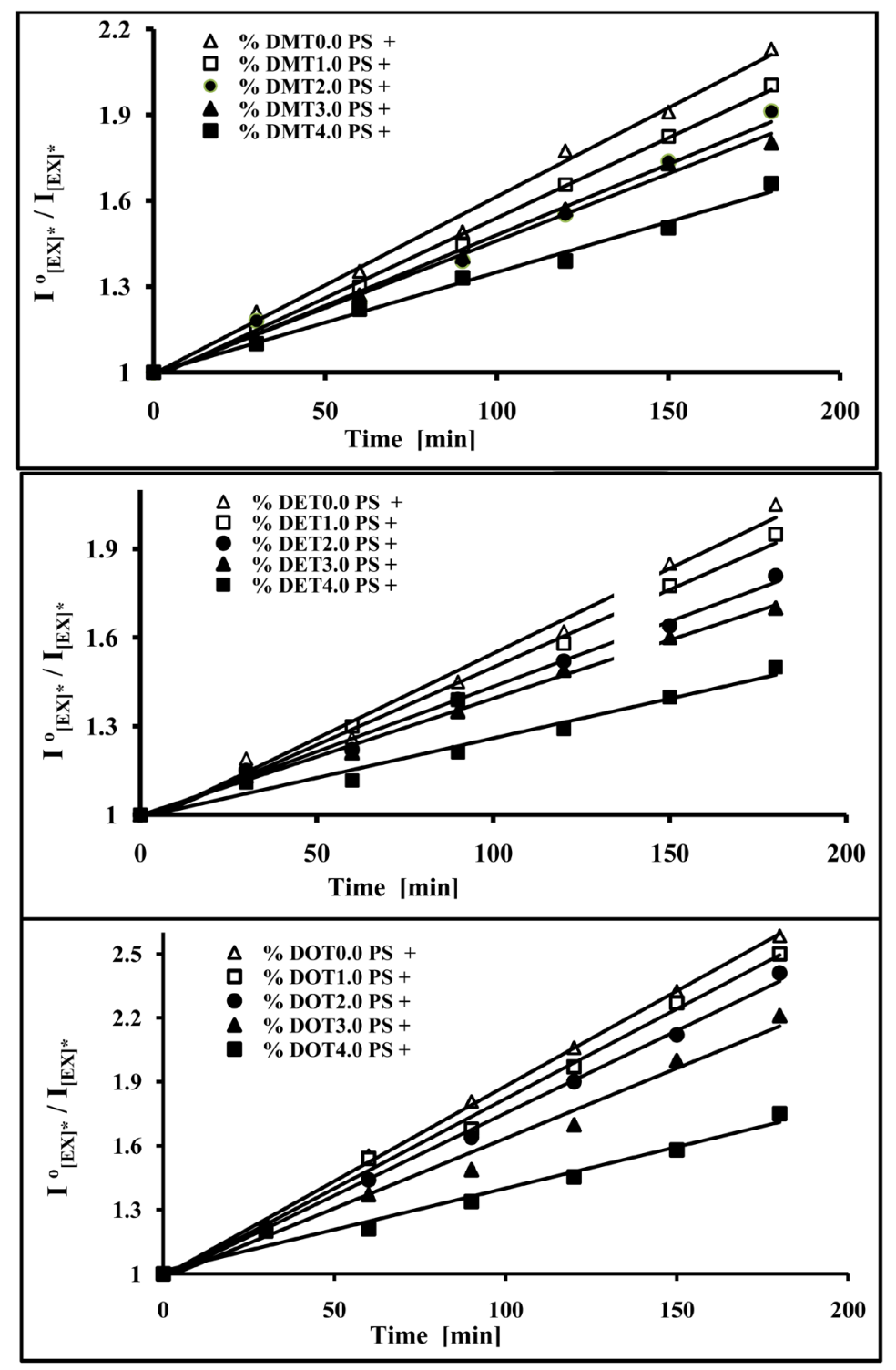

Figure 4. Effect of added mass percent of DMT, DET and DOT on excimer fluorescence quenching of blended PS films at different irradiation times $(0-180 \mathrm{~min})$.

transfer complex tends to be more stable than that of [PS-phthalate] energy transfer complex, towards UV-irradiation. On the other hand, the increase in the molar mass of the plasticizer may also decrease the stability of the polymer towards UV irradiation by decrease in the stability of the energy transfer complex.

As can be seen from Figure 7, the photo-quenching rate constant of excimer fluorescence increases with the increase in molar mass of the used phthalate and terephthalate plasticizers; a fact that correlates well with that obtained for the thermal degradation of SPS [16] [19]. The increase in the efficiency of excimer fluorescence photo-quenchingrate constant $\left(\Delta k_{P Q}\right)$ with the increase in molar mass of added plasticizers is shown in Figure 7.

The increase in the photo-quenching rate constant $\left(k_{P Q}\right)$ with the increase in the molar mass of both phthalate and terephthalate plasticizers indicated that the stability of irradiated polymer chromophores decrease, and may enhance the photodegradation of polymeric chains. Furthermore, it is more likely that the increase in the bulkiness of plasticizer molecules caused enhancement to thephotodegradation efficiency of polymeric chromophores.

The increase in the percentage of added plasticized showed a lowering in the photo-quenching rate constant 


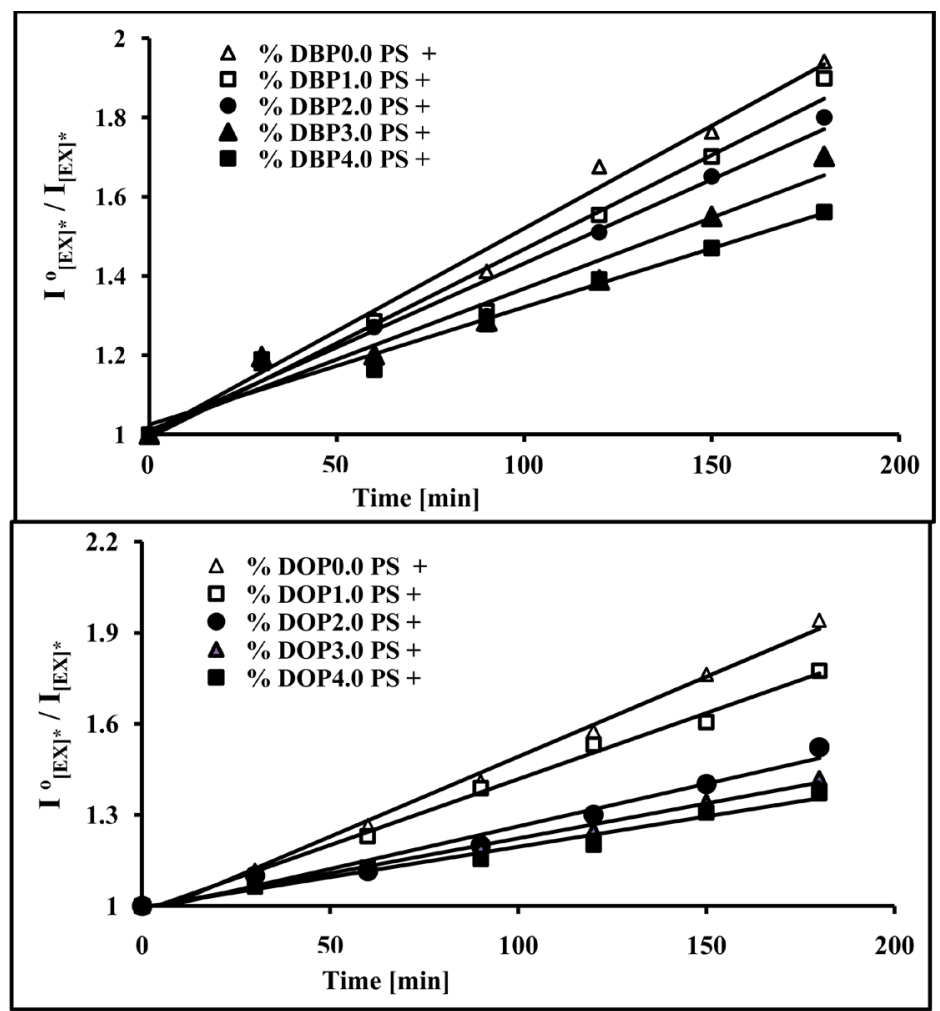

Figure 5. Effect of added mass percent of DBP, and DOP on excimer fluorescence quenching of blended PS films at different irradiation times (0 - $180 \mathrm{~min})$.

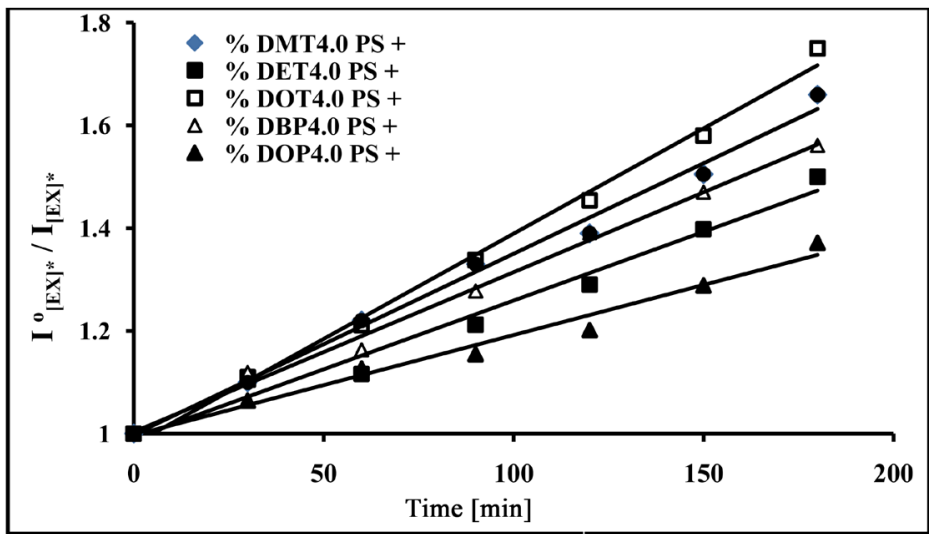

Figure 6. Effect of added $4.0 \%$ of DMT, DET, DOT, DBP, and DOP on excimer fluorescence quenching of blended PS films at different irradiation times.

$\left(k_{P Q}\right)$, as shown in Figure 8.

As can be seen from Figure 8, the increase in amount of added plasticizer caused a decrease in the photoquenching rate constant of irradiated polymer, and found to depend upon the structure of the plasticizer molecules. Phthalate plasticizers showed a lower efficiency of photo-quenching in comparison with that obtained with terephthalate plasticizers.

The corresponding fluorescence photo-quenching values $\left(k_{P Q}\right)$ and the efficiency of photo-quenching ratio $\left(\left(I_{E X}^{o} / I_{E X}\right)^{*}\right)$ of pure and blended PS films are shown in Table 2. 


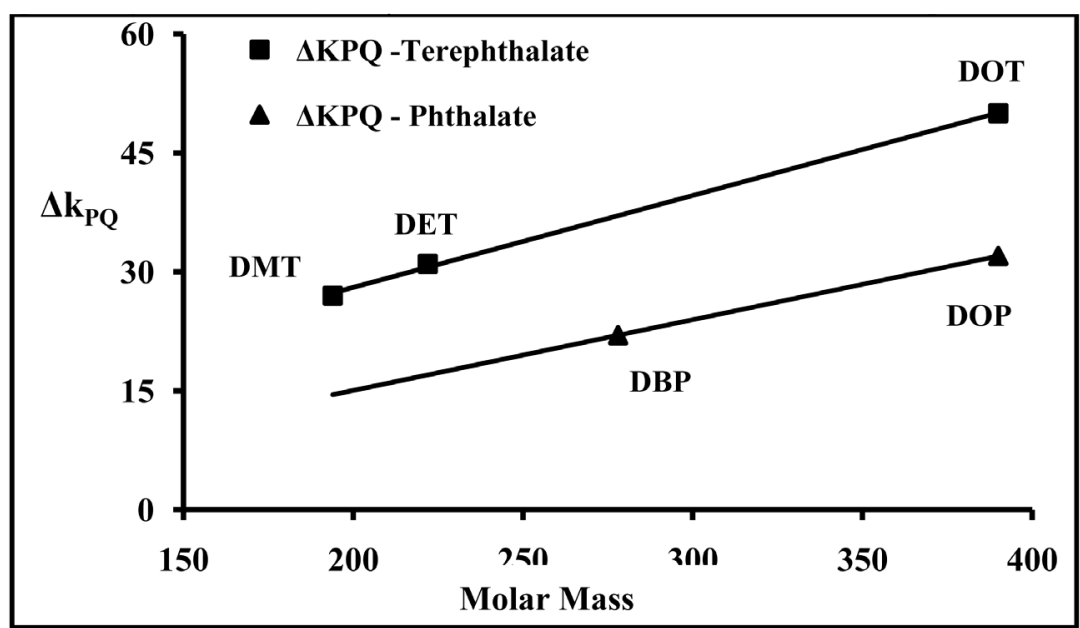

Figure 7. Effect of molar mass of the added plasticizer on the change in the photo-quenching rate constant $\left(\Delta k_{P Q} \times 10^{-4}\right)$ of polystyrene irradiated films.

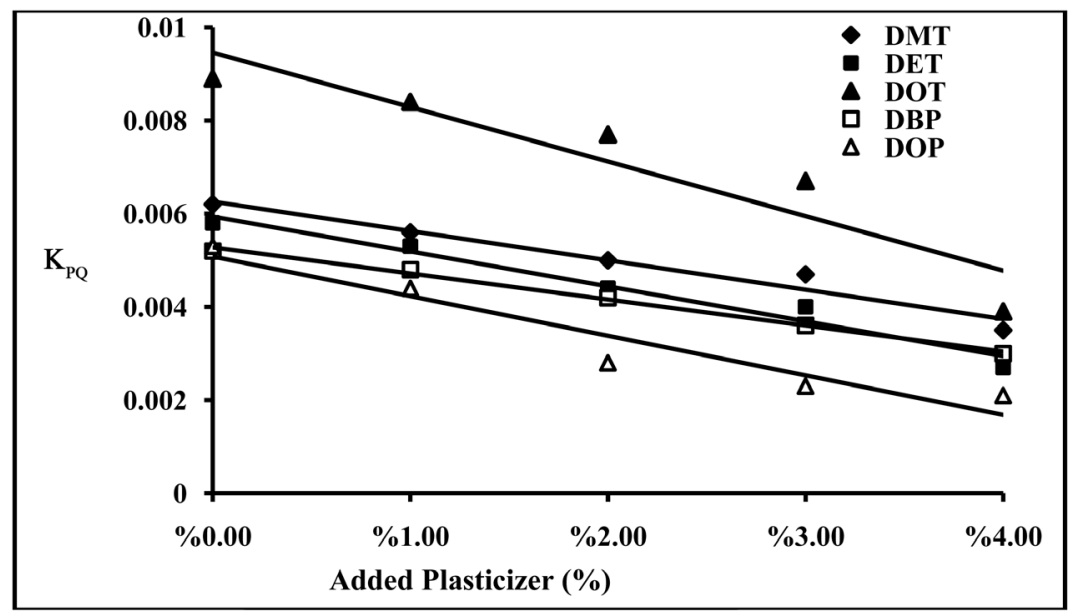

Figure 8. Effect added percentage of DMT, DET, DOT, DBP and DOP on the photo-quenching rate constant $\left(k_{P Q}\right)$ of polystyrene irradiated films.

It was reported that the photo-oxidation mechanism of PS chromophores in solid films is dependant upon the rate of oxygen diffusion into the polymer matrix, and to the formation of charge transfer complexes between polymer chromophores and oxygen molecules [32]-[34]. The rate of photo-oxidation is dependant upon the reactivity of oxygen molecules with the formed radicals in polymeric matrix. A combination of these formed macro-radicals may lead to cross-linking [35]. A more detailed discussion on the processes involved in the oxidative degradation in polymeric chains, has been reported by Rabek [4]. The photo-oxidative degradation in PS chromophores is free radical chain mechanism which occurs when polymeric chains are exposed to UV-radiations in presence of air [36].

If we consider the photo-quenching rate constant $\left(k_{P Q}\right)$ is an indication of efficiency of the photodegradation of PS chromophores, then blending of PS films showed an increase in the efficiency of photodegradation process, while the increase in the percent of added plasticizers caused a decrease in the efficiency of photodegradation of polymeric chains and to some extent, stabilizes the polymer towards irradiation. Another factor is that these plasticizers showed a small absorption in the region of absorption of polystyrene, thus they may act as a UV-absorbers.

\subsection{FT-IR-Spectra of Irradiated and Non-Irradiated Pure and Blended Polystyrene Films}

The photodegradation processes of irradiated pure and blended PS films are further reconfirmed by measuring 
Table 2. Relative intensities of the ratio $\left(I_{E X}^{o} / I_{E X}\right)^{*}$ for intensities of excimer fluorescence bands and excimer fluorescence photo-quenching rate constant values $\left(k_{P Q}\right)$ of irradiated pure and blended PS films.

\begin{tabular}{|c|c|c|c|c|c|c|}
\hline \multirow{2}{*}{$\begin{array}{c}\text { Polymer } \\
\boldsymbol{k}_{\mathrm{PQ}}(\mathbf{n m}) \\
\text { PS }\end{array}$} & \multirow{2}{*}{$\begin{array}{c}\lambda_{\text {(emiss.) }} \\
327\end{array}$} & \multicolumn{2}{|c|}{ Plasticizer (\%) } & \multirow{2}{*}{$\begin{array}{c}\text { Time (min.) } \\
0.993\end{array}$} & \multirow{2}{*}{$\begin{array}{c}\mathbf{R}^{2} \\
2.129\end{array}$} & \multirow{2}{*}{$\begin{array}{r}\left(I_{E X}^{o} / I_{E X}\right) \\
0.0062\end{array}$} \\
\hline & & DMT, $0.0 \%$ & 180 & & & \\
\hline PS & 329 & DMT, $1.0 \%$ & 180 & 0.996 & 2.004 & 0.0056 \\
\hline PS & 331 & DMT, $2.0 \%$ & 180 & 0.988 & 1.913 & 0.0050 \\
\hline PS & 333 & DMT, $3.0 \%$ & 180 & 0.993 & 1.802 & 0.0047 \\
\hline PS & 334 & DMT, $4.0 \%$ & 180 & 0.992 & 1.660 & 0.0035 \\
\hline PS & 327 & DET, $0.0 \%$ & 180 & 0.971 & 2.051 & 0.0058 \\
\hline PS & 328 & DET, $1.0 \%$ & 180 & 0.987 & 1.955 & 0.0053 \\
\hline PS & 332 & DET, $2.0 \%$ & 180 & 0.994 & 1.809 & 0.0044 \\
\hline PS & 333 & DET, $3.0 \%$ & 180 & 0.994 & 1.710 & 0.0040 \\
\hline PS & 336 & DET, $4.0 \%$ & 180 & 0.991 & 1.552 & 0.0027 \\
\hline PS & 327 & DOT, $0.0 \%$ & 180 & 0.998 & 2.584 & 0.0089 \\
\hline PS & 331 & DOT, $1.0 \%$ & 180 & 0.994 & 2.510 & 0.0084 \\
\hline PS & 338 & DOT, $2.0 \%$ & 180 & 0.998 & 2.402 & 0.0077 \\
\hline PS & 342 & DOT, $3.0 \%$ & 180 & 0.984 & 2.214 & 0.0067 \\
\hline PS & 344 & DOT, $4.0 \%$ & 165 & 0.978 & 1.755 & 0.0039 \\
\hline PS & 327 & DBP, $0.0 \%$ & 180 & 0.930 & 1.941 & 0.0052 \\
\hline PS & 329 & DBP, $1.0 \%$ & 180 & 0.935 & 1.889 & 0.0048 \\
\hline PS & 330 & DBP, $2.0 \%$ & 180 & 0.949 & 1.800 & 0.0042 \\
\hline PS & 333 & DBP, $3.0 \%$ & 180 & 0.995 & 1.702 & 0.0036 \\
\hline PS & 334 & DBP, $4.0 \%$ & 180 & 0.968 & 1.561 & 0.0030 \\
\hline PS & 327 & DOP, $0.0 \%$ & 180 & 0.9595 & 1.945 & 0.0053 \\
\hline PS & 328 & DOP, $1.0 \%$ & 180 & 0.994 & 1.775 & 0.0044 \\
\hline PS & 330 & DOP, $2.0 \%$ & 180 & 0.973 & 1.523 & 0.0028 \\
\hline PS & 331 & DOP, $3.0 \%$ & 180 & 0.993 & 1.420 & 0.0023 \\
\hline PS & 332 & DOP, $4.0 \%$ & 180 & 0.978 & 1.374 & 0.0021 \\
\hline
\end{tabular}

their FT-IR absorption spectra. It has been reported that irradiation of pure polystyrene films resulted in changes in the FT-IR absorption spectra [9] [37]. FT-IR spectra of non-irradiated and irradiated PS films before and after irradiations for 2.0 hours were recorded immediately before and after irradiationas shown in Figure 9.

As can be seen from Figure 9, the effect of irradiated film caused the increase in the intensity of some absorption bands, and the formation of new absorption bands as a result of the photodegradation and photo-oxidation processes of polymeric chains.

The FT-IR absorption spectra of non-irradiated and irradiated blended PS films with $4.0 \%$ DMT, for 0.0 and 2.0 hours, is shown in Figure 10.

As can be noticed from Figure 9 and Figure 10, modifications occur in the intensity of different absorption bands in the FT-IR spectra of the irradiated pure and blended PS films. These changes correspond to photooxidation and photodegradation of polymeric chains [30]. Transformation is clearly demonstrated by the decrease in absorbance of the bands at $3800-3400 \mathrm{~cm}^{-1}$, and by the formation of new absorption band corresponding to new compounds resulting from the polymer chains photodegradation in different regions. It has been 


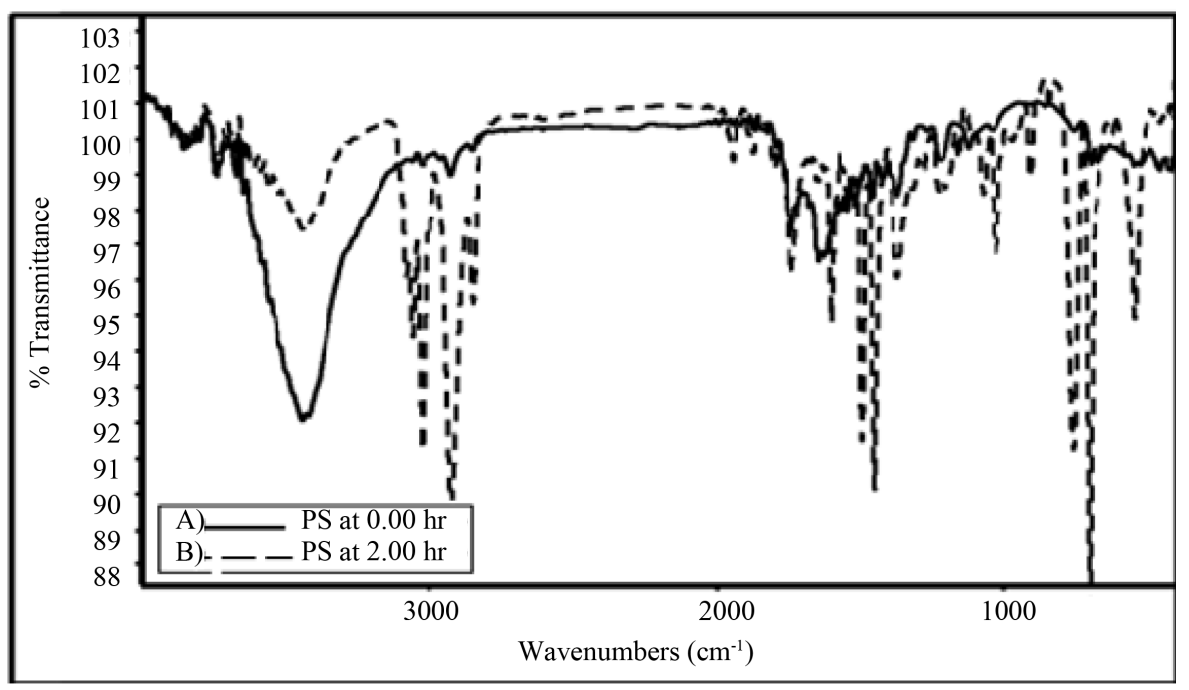

Figure 9. FT-IR absorption spectra of non-irradiated and irradiated pure (PS) films, for 0.0 and 2.0 hours.

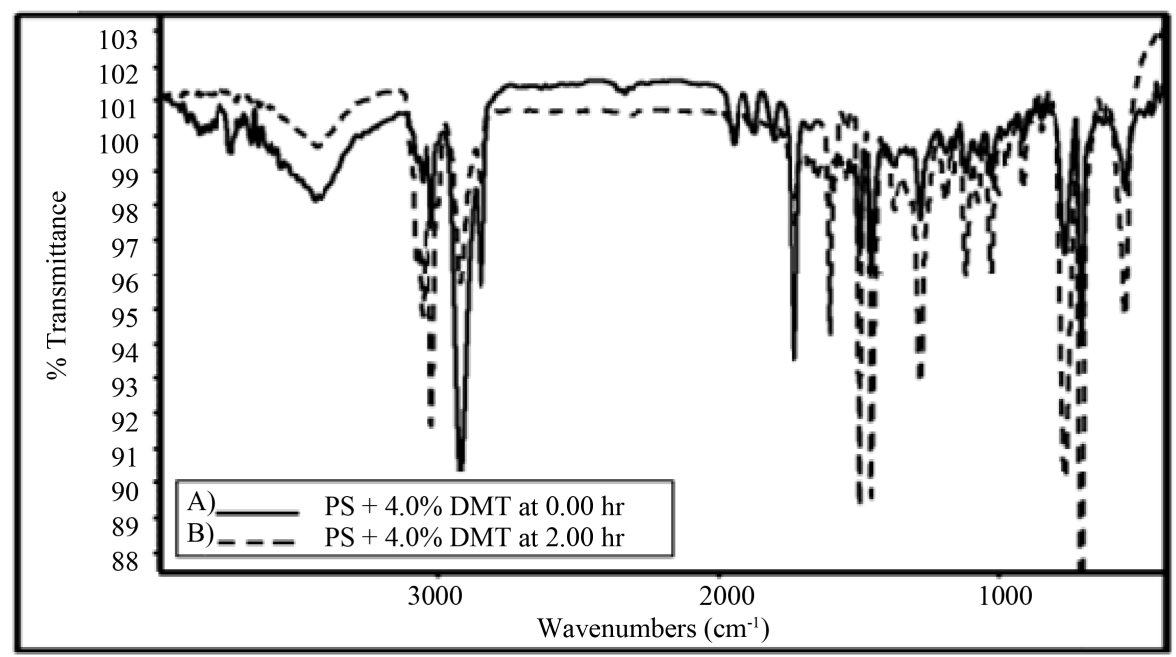

Figure 10. FT-IR absorption spectra of non-irradiated and irradiated blended PS films with $4.0 \%$ DMT for 0.0 and 2.0 hours.

reported that the presence of the absorption band at $3440 \mathrm{~cm}^{-1}$ is related to the increase in the photo-oxidation of benzene rings [38]. The decrease in the intensity of absorption at $3440 \mathrm{~cm}^{-1}$ with the increase in irradiation time may influence the increase in the photo-oxidation of benzene ring and a decrease in atomicity in the polymer sample. Rabek and Ranby [38] have reported during irradiation of polystyrene films, three cases of oxidation of the benzene ring being observed. The formation of benzyl acetophenone chromophores; acetophenone structures; and conjugated double bonds, were the main products resulted from the photo-oxidation of polystyrene films. The same observations were observed in the UV-irradiation of SPS solid films [15] [39].

As can be noticed from Figure 9 and Figure 10 and Table 3, the increase in irradiation time, resulted in the increase in the absorption intensity of the band at $1740 \mathrm{~cm}^{-1}(\mathrm{C}=\mathrm{O}$ stretch $)$, and the formation of new band at $1450 \mathrm{~cm}^{-1},(\mathrm{C}=\mathrm{C}$ stretch$)$, may also influence the formation of carbonyl compound and diene type structures during the photo-oxidation and photodegradation of polymeric chromophores. However, the interpretations of these bands are not simple because of the overlapping of the different types of carbonyl species in the same frequency range.

The FT-IR analysis of irradiated PS films blended with Dimethyl terephthalate plasticizers showed some changes in the absorption bands upon blending. The intensity of the $\mathrm{sp}^{3}$ carbon hydrogen stretching vibration 
Table 3. FT-IR absorption band positions in PS and PS films blended with 4\% DMT, before and after, $(0.0 \mathrm{hr}$, and $2.0 \mathrm{hrs})$ of irradiation, at $\left(\lambda_{\mathrm{ext}}=265 \mathrm{~nm}\right)$.

\begin{tabular}{|c|c|c|c|c|c|}
\hline \multirow{2}{*}{$\begin{array}{c}\text { Polymer } \\
\text { PS }\end{array}$} & \multirow{2}{*}{$\begin{array}{c}\text { Band }\left(\mathbf{c m}^{-1}\right) \\
3444\end{array}$} & \multicolumn{2}{|c|}{$\begin{array}{l}\text { Time of Irradiation } \\
0.0 \mathrm{hr} 2.0 \mathrm{hrs}\end{array}$} & \multirow{2}{*}{$\begin{array}{c}\text { Type of Vibration } \\
\text { C-H stretch in benzene }\end{array}$} & \multirow{2}{*}{$\begin{array}{r}\text { Intensity } \\
\text { Decreased }\end{array}$} \\
\hline & & 3445 & 3445 & & \\
\hline PS & 3059 & ----- & 3060 & $=\mathrm{C}-\mathrm{H}$ stretch & New Band \\
\hline PS & 3026 & ----- & 3027 & $=\mathrm{C}-\mathrm{H}$ stretch & New Band \\
\hline PS & 2921 & 2923 & 2924 & $(\mathrm{C}-\mathrm{H})$, stretching vibration of benzene & Increased \\
\hline PS & 2842 & 2842 & 2851 & $\mathrm{C}-\mathrm{H}$ stretch in aldehydes & Increased \\
\hline PS & 1740 & 1741 & 1741 & $\mathrm{C}=\mathrm{O}$ stretch & Increased \\
\hline PS & 1490 & ------ & 1492 & $\mathrm{C}=\mathrm{C}$ stretch & New Band \\
\hline PS & 1024 & ------ & 1024 & $\mathrm{C}-\mathrm{O}-\mathrm{C}$ antisymmetric stretching vibration & New Band \\
\hline PS & 755 & ------ & 756 & Conjugated double bond & New Band \\
\hline PS & 541 & 542 & 542 & Mono substitution of benzene ring & Decreased \\
\hline PS/DMT & 3738 & 3738 & ----- & C-O-C stretching vibration & Disappears \\
\hline PS/DMT & 3446 & 3446 & 3431 & $\mathrm{C}-\mathrm{H}$ stretch in benzene & decreased \\
\hline $\mathrm{PS} / \mathrm{DMT}$ & 3059 & 3059 & 3060 & $(\mathrm{C}-\mathrm{H})$, stretching vibration of benzene & Increased \\
\hline PS/DMT & 3026 & 3026 & 3027 & C-H stretch & Increased \\
\hline PS/DMT & 2923 & 2924 & 2924 & $\mathrm{C}-\mathrm{H}$ stretch in aldehydes & increased \\
\hline $\mathrm{PS} / \mathrm{DMT}$ & 2850 & 2851 & 2853 & & Increased \\
\hline $\mathrm{PS} / \mathrm{DMT}$ & 1726 & ------ & 1727 & $\mathrm{C}=\mathrm{O}$ stretch, carboxylic acid & New Band \\
\hline $\mathrm{PS} / \mathrm{DMT}$ & 1600 & ------ & 1602 & $\mathrm{C}=\mathrm{C}$ stretch & New Band \\
\hline $\mathrm{PS} / \mathrm{DMT}$ & 1451 & 1452 & 1453 & $\begin{array}{c}\mathrm{C}=\mathrm{O} \text { stretch vibrations, Carboxylic acids-dimeric } \\
\text { forms }\end{array}$ & Decreased \\
\hline $\mathrm{PS} / \mathrm{DMT}$ & 1274 & 1275 & 1276 & $\mathrm{C}-\mathrm{O}$ stretch in acids & Increased \\
\hline PS / DMT & 1024 & 1024 & 1026 & $\mathrm{C}-\mathrm{O}-\mathrm{C}$ antisymmetric stretching vibration & Increased \\
\hline $\mathrm{PS} / \mathrm{DMT}$ & 830 & 830 & 831 & Conjugated double bond & Increased \\
\hline PS / DMT & 699 & 670 & 670 & $=\mathrm{C}-\mathrm{H}$ bending & Increased \\
\hline PS / DMT & 541 & 542 & 542 & Mono substitution of benzene ring & Decreased \\
\hline
\end{tabular}

increases as the polymer was blended with DMT, and also by the increase in exposure time of irradiation especially $2923 \mathrm{~cm}^{-1}$, which is assigned as the $\mathrm{C}-\mathrm{H}$ stretching. The $\mathrm{C}=\mathrm{C}$ double bond stretching at $1600 \mathrm{~cm}^{-1}$ and the absorption peak at $1024 \mathrm{~cm}^{-1}$, assigned to the $\mathrm{C}-\mathrm{O}-\mathrm{C}$ antisymmetric stretching vibration increased with plasticization and with irradiation of polymer films, as shown in Table 3. The peak at $1727 \mathrm{~cm}^{-1}$ was assigned to the growth of aliphatic ketones formed from the reaction of the reactive alkoxy radicals; it is more likely that the formed photoproduct could be an acetophenone group which further reacted with the subsequent formation of benzoic acid [40].

Also the FT-IR absorption spectra of blended PS with DMT, showed a slight shift in the bands maxima, as well as the appearance of new bands at, $\left(1726 \mathrm{~cm}^{-1}, \mathrm{C}=\mathrm{O}\right.$ stretch $),\left(1602 \mathrm{~cm}^{-1}, \mathrm{C}=\mathrm{C}\right.$ stretch $)$ and the changes in the intensities of many other absorption bands with the same bands for the non-irradiated blended samples. The shift in absorption bands as well as the formation of new absorption bands upon irradiation of PS films is good indication of the conformational changes in the polymeric chromophores, and the increases in the efficiency of photogegradation of polymeric chains.

The modifications that occurred at different zones of the FT-IR absorption spectra of the irradiated pure and blended PS with 4.0\% DMT permit characterization these modifications in the following points:

1) At high region of the FT-IR spectra, the absorption band at $3444 \mathrm{~cm}^{-1}$, a noticeable increase in the intensity of the absorption band is observed in doped polymer; on the other hand, a very small decrease was observer in the irradiated polymer that can be ascribed to a carboxylic acid group [41]; 
2) The intensity of the absorption spectra of irradiated PS film showed an increase in the intensity of a broad band between $2924 \mathrm{~cm}^{-1}$ and $2850 \mathrm{~cm}^{-1}$, which were assigned to the $(\mathrm{C}-\mathrm{H})$, stretching vibration of benzene, and the latter was found to increase in its intensity with the increase of time of irradiation. Such observation, suggests that a photodegradation of PS chains occurs through the oxidation of benzene rings [42];

3) In the FT-IR absorption spectra of irradiated PS film, the complex region of the C-O stretch $\left(1741 \mathrm{~cm}^{-1}\right)$ and $\left(1024 \mathrm{~cm}^{-1}\right)$ assigned to the C-O-C bend vibrations, showed an increase in the absorbance throughout the increase in irradiation times of polymer films, which becomes higher in the case of irradiated blended polymer. The $\mathrm{C}=\mathrm{C}$ double bond stretching at $1602 \mathrm{~cm}^{-1}$ and other absorption peaks which increased with plasticization and with the increase in irradiation time, could suggest the formation of mono-substituted benzene rings [40];

4) The FT-IR absorption spectra, of PS films blended with 4.0\% DMT, showed a noticeable formation of new broad bands centered at $\left(1726 \mathrm{~cm}^{-1}, \mathrm{C}=\mathrm{O}\right.$ stretch $)$, and $\left(1602 \mathrm{~cm}^{-1}, \mathrm{C}=\mathrm{C}\right.$ stretch $)$, and their intensities were found to increase with the increase in irradiation time and also with the increase in the amount of added plasticizer, and normally assigned to the growth of aliphatic ketones formed from the reaction of the reactive alkoxy radicals. It is more likely that the formed photoproduct could be an acetophenone group which further reacted with the subsequent formation of benzoic acid [43] [44];

5) The band observed at $830 \mathrm{~cm}^{-1}$, as can be noted in the spectra of the blended polymer, can suggest the formation of conjugated double bond sequences in the main polymer chains. The same band was observed by Grassie and Weir on photo-oxidation of polystyrene [34].

\section{Conclusions}

According to the changes in the intensities of absorption spectra, fluorescence spectra and FT-IR absorption spectra for pure and blended PS films with phthalate and terephthalate plasticizers, the following conclusions can be summarized as follows:

1) The absorption spectra of irradiated pure and blended PS films showed an increase in the intensity of the absorption band, as well the formation of new absorption broad band at longer wavelength $(280-330 \mathrm{~nm})$. The intensity of the formed broad band increased with increase in irradiation time and with the increase in the amount of added plasticizers. These changes are good indications of the possible formation of new photo-products resulted from the photodegradation of polymeric chains;

2) Irradiation of pure and blended PS films in presence of air led to important modification to fluorescence bands. These modifications were decrease in the intensity of excimer fluorescence, and formation of new emission band with no clear maxima at longer wavelength $(382-500 \mathrm{~nm})$ in blended polymer. These modifications indicate that there is a possibility of photodegradation in the polymeric chains. The degradation effect was found to increase by the increase in molar mass of the used plasticizer;

3) From the FT-IR spectra of irradiated of pure and blended PS films, a noticeable change was observed by the formation of new absorption bands, as well as, the change in the intensity of many absorption bands (decrease of some and increase of most of the others). This clearly indicates the photodegradation of the polymeric chains, and this change increases with the increase in time of irradiation, and increase in the amount of added plasticizers;

4) The Al Ani-Hawi equation (Equation (3)) was used to evaluate some kinetic parameters such as the quenching efficiency ratio $\left(I_{E X}^{o} / I_{E X}\right)^{*}$ and the quenching rate constant $\left(k_{P Q}\right)$. The increase in the photo-quenching rate constant with the increase in the molar mass of both phthalate and terephthalate plasticizers indicates the stability of irradiated polymer chromophores decrease, and may increase the photodegradation of polymeric chains;

5) The increase in amount of added plasticizer decreases the stability of irradiated blended polymer chains and is found to depend upon the molecular structure of the plasticizer molecules. Phthalate plasticizers showed a lower efficiency of photo-quenching in comparison with that obtained with terephthalate plasticizers.

\section{References}

[1] Odian, G. (2004) Principle of Polymerization. John Wiley \& Sons, New York.

[2] Stuart, B.H. (2002) Polymer Analysis. John Wiley \& Sons, New York, 250. 
[3] Ranby, B. and Rabek, J.F. (1974) Studies on the Photooxidation Mechanism of Polymers. I. Photolysis and Photooxidation of Polystyrene. Journal of Polymer Science: Polymer Chemistry Edition, 12, 273-294. http://dx.doi.org/10.1002/pol.1974.170120203

[4] Rabek, J.F. (1995) Polymer Photodegradation, Mechanisms and Experimental Methods. Chapman and Hall, London. http://dx.doi.org/10.1007/978-94-011-1274-1

[5] Otocka, E.P. (1983) Photooxidation of Polystyrene: Irradiation at 254 and $365 \mathrm{~nm}$. Journal of Applied Polymer Science, 28, 3227-3233. http://dx.doi.org/10.1002/app.1983.070281017

[6] Geuskens, G., Bastin, P., Lu-Vinh, Q. and Rens, M. (1981) Photo-Oxidation of Polymers: Part IV-Influence of the Processing Conditions on the Photo-Oxidative Stability of Polystyrene. Polymer Degradation and Stability, 3, 295306. http://dx.doi.org/10.1016/0141-3910(81)90025-2

[7] Kuzina, S.I. and Mikhailov, A.I. (2001) Photo-Oxidation of Polymers 4. The Dual Mechanism of Polystyrene Photo-Oxidation: A Hydroperoxide and a Photochain One. European Polymer Journal, 37, 2319-2325. http://dx.doi.org/10.1016/S0014-3057(01)00028-3

[8] Lawrence, J.B. and Weir, N.A. (1973) Photodecomposition of Polystyrene on Long-Wave Ultraviolet Irradiation: A Possible Mechanism of Initiation of Photooxidation. Journal of Polymer Science: Polymer Chemistry Edition, 11, 105118. http://dx.doi.org/10.1002/pol.1973.170110109

[9] Mailhot, B. and Gardette, J.L. (1992) Polystyrene Photooxidation. 1. Identification of the IR-Absorbing Photoproducts Formed at Short and Long Wavelengths. Macromolecules, 25, 4119-4126. http://dx.doi.org/10.1021/ma00042a012

[10] Rosenberg, R.A., Simons, J.K., Chen, J.M. and Taylor, J.W. (1993) Fluorescence Studies of the Vacuum Ultraviolet, Synchrotron Radiation-Induced Photochemistry of Polystyrene. Macromolecules, 26, 3262-3266. http://dx.doi.org/10.1021/ma00065a003

[11] Weir, N.A. (1982) Developments in Polymer Degradation (Edited by N. Grassie). Applied Science, London, 143.

[12] Kobatake, A.T., Okisaki, F. and Shuyama, H. (1995) Photodegradation of Polystyrene Containing Flame-Retardants: Wavelength Sensitivity and Efficiency of Degradation. Polymer Degradation and Stability, 50, 261-267. http://dx.doi.org/10.1016/0141-3910(95)00143-3

[13] Choi, W.M., Jung, I.D., Sik, C. and Cho, W. (1998) Syntheses and Properties of Photodegradable Polystyrene-Containing Carbonyl Group. Journal of Applied Polymer Science, 67, 1237-1242. http://dx.doi.org/10.1002/(SICI)1097-4628(19980214)67:7<1237::AID-APP11>3.0.CO;2-Z

[14] Al Ani, K.E. and Ramadhan, A.E. (2010) Plasticization Effect on the Photodegradation of Poly(4-chlorostyrene) and Poly(4-bromostyrene) Films. Material Science and Applications, 1, 358-368. http://dx.doi.org/10.4236/msa.2010.16052

[15] Al Ani, K.E. and Hawi, M.A. (2009) Effect of Plasticization on the Photodegradation of Poly(para-methoxystyrene) Films. Journal of Material Science, 44, 2674-2682. http://dx.doi.org/10.1007/s10853-009-3350-x

[16] Al Ani, K.E. and Anabtawi, M. (2012) UV-Irradiation Effect on the Photodegradation of Plasticized Poly(ortho, meta, and para-fluorostyrene) Isomers in Solid Films. International Journal of Chemistry, 4, 62-84. http://dx.doi.org/10.5539/ijc.v4n5p62

[17] Al Ani, K.E. and Ramadhan, A.E. (2010) Study of the Influence of UV-Irradiation on the Photodegradation of Plasticized Poly(para-tert-butylstyrene) Films. International Journal of Material Research, 101, 1554-1562. http://dx.doi.org/10.3139/146.110434

[18] Al Ani, K.E. and Suleiman, A.M. (2007) Substituent Effect on the Fluorescence Quenching of Polystyrene Derivatives by Polymeric Plasticizers. Journal Photochemistry and Photobiology A: Chemistry, 188, 177-184.

[19] Weir, N.A. and Milkie, T.H. (1979) Photochemistry of Ring-Substituted Polystyrenes. II. Photolyses of Poly(P-fluoro-, P-Chloro-, and P-bromostyrene)s. Journal of Polymer Science: Polymer Chemistry Edition, 17, 3735-3749. http://dx.doi.org/10.1002/pol.1979.170171129

[20] Ramadhan, A.E., Ahmed, R.K. and Al Ani, K.E. (2006) Thermal Effect and Quenching of Exciplex Fluorescence of Polystyrene Derivatives by Dimethyl Terephthalate in Solid Films. Polymer Journal, 38, 355-363. http://dx.doi.org/10.1295/polymj.38.355

[21] Weir, N.A. (1878) Reactions of Hydroxyl Radicals with Polystyrene. European Polymer Journal, 14, 9-14. http://dx.doi.org/10.1016/0014-3057(78)90144-1

[22] David, C., Baeyens-Volant, D., Delaunois, G., Lu-Vinh, Q., Piret, W. and Geuskens, G. (1978) Photo-Oxidation of Polymers-III. European Polymer Journal, 14, 501-507. http://dx.doi.org/10.1016/0014-3057(78)90037-X

[23] Geuskens, G., Bastin, P., Lu-Vinh, Q. and Rens, M. (1981) Photo-Oxidation of Polymers: Part IV-Influence of the Processing Conditions on the Photo-Oxidative Stability of Polystyrene. Polymer Degradation and Stability, 3, 295-306. http://dx.doi.org/10.1016/0141-3910(81)90025-2 
[24] Geuskens, G., Baeyens-Volant, D., Delaunois, G., Lu-Vinh, Q., Piret, W. and David, C. (1978) Photo-Oxidation of Polymers-I. European Polymer Journal, 14, 291-297. http://dx.doi.org/10.1016/0014-3057(78)90051-4

[25] Tovborg Jensen, J.P., and Kops, J.J. (1981) Energy Transfer in Connection with the Photo-Oxidation of Polystyrene and Its Blends with Poly(2,6-dimethyl-1,4-phenylene oxide). Journal of Polymer Science: Polymer Chemistry Edition, 19, 2765-2771.

[26] Kaczmarek, H. (1995) Photodegradation of Polystyrene and Poly(vinyl acetate) Blends-II. Irradiation of PS/PVAc Blends by Fluorescent Lamp. European Polymer Journal, 31, 1175-1184. http://dx.doi.org/10.1016/0014-3057(95)00095-X

[27] Kaczmarek, H. (1995) Photodegradation of Polystyrene and Poly(vinyl Acetate) Blends - I. Irradiation of PS/PVAc Blends by Polychromatic Light. European Polymer Journal, 31, 1037-1042. http://dx.doi.org/10.1016/0014-3057(95)00094-1

[28] Subramanian, K. (2002) Photodecomposition of Poly(styrene peroxide). European Polymer Journal, 38, $1167-1173$. http://dx.doi.org/10.1016/S0014-3057(01)00297-X

[29] Torikai, A., Takeuch, T. and Fueki, K. (1983) Photodegradation of Polystyrene and Polystyrene Containing Benzophenone. Polymer Photochemistry, 4, 307-320. http://dx.doi.org/10.1016/0144-2880(83)90038-6

[30] Millan, M.D., Locklin, J., Fulghum, T., Baba, A. and Advincula, R.C. (2003) Polymer Thin Film Photodegradation and Photochemical Crosslinking: FT-IR Imaging, Evanescent Waveguide Spectroscopy, and QCM Investigations. Polymer, 46, 5556-5568. http://dx.doi.org/10.1016/j.polymer.2005.05.050

[31] Al Safi, S.A., Al Mouamin, T.M., Al Sieadi, W.N. and Al Ani, K.E. (2014) Irradiation Effect on Photodegradation of Pure and Plasticized Poly(4-methylstyrene) in Solid Films. Material Science and Applications, 5, 300-315. http://dx.doi.org/10.4236/msa.2014.55036

[32] Tse, K.C., Ng, F.M. and Yu, K.N. (2006) Photo-Degradation of PADC by UV Radiation at Various Wavelengths. Polymer Degradation and Stability, 91, 2380-2388. http://dx.doi.org/10.1016/j.polymdegradstab.2006.03.017

[33] Luengo, C., Allen, N.S., Edge, M., Wilkinson, A., Parellada, M., Barrio, J.A. and Santa, R. (2006) Photo-Oxidative Degradation Mechanisms in Styrene-Ethylene-Butadiene-Styrene (SEBS) Triblock Copolymer. Polymer Degradation and Stability, 91, 947-956. http://dx.doi.org/10.1016/j.polymdegradstab.2005.06.017

[34] Grassie, N. and Wier, N.A. (1965) The Photooxidation of Polymers. II. Photolysis of Polystyrene. Journal of Applied Polymer Science, 9, 975-986. http://dx.doi.org/10.1002/app.1965.070090315

[35] Tamai, T., Hashida, I., Ichinose, N., Kawanishi, S., Inoue, H. and Mizuno, K. (1996) U.v.-Irradiation of Thin Films of Polystyrene Derivatives: Formation of Carboxylic Group and Crosslinking from 4-Trimethylsilylmethyl Substituent. Polymer, 37, 5525-5528. http://dx.doi.org/10.1016/S0032-3861(96)00438-7

[36] White, K.R. and Shyichuk, A.V. (2007) Effect of Stabilizer on Scission and Crosslinking Rate Changes during Photo-Oxidation of Polypropylene. Polymer Degradation and Stability, 92, 2095-2101. http://dx.doi.org/10.1016/j.polymdegradstab.2007.07.013

[37] Ranby, B. and Rabek, J.F. (1975) Photodegradation of Polymers. Wiley, New York, 165.

[38] Rabek, J.F. and Ranby, B. (1974) Studies on the Photooxidation Mechanism of Polymers. II. The Role of Quinones as Sensitizers in the Photooxidative Degradation of Polystyrene. Journal of Polymer Science: Polymer Chemistry Edition, 12, 295-306. http://dx.doi.org/10.1002/pol.1974.170120204

[39] Zhang, Z., Hu, X. and Luo, Z. (1996) Wavelength Sensitivity of Photooxidation of Polypropylene. Polymer Degradation and Stability, 51, 93-97. http://dx.doi.org/10.1016/0141-3910(95)00210-3

[40] Pouchert, C.J., Ed. (1985) The Aldrich Library of Infrared Spectra. 3rd Edition, Aldrich Co., Milwaukee.

[41] Lin-Vein, D., Colthup, N.B., Fately, W.G. and Grassley, J.G. (1991) The Handbook of Infrared and Raman Characteristic Frequencies of Organic Molecules. Academic Press, Boston.

[42] Bera, M., Rivaton, A., Gandon, G. and Gardette, J.L. (2000) Photooxidation of Poly(para-xylylene). European Polymer Journal, 36, 1753-1764. http://dx.doi.org/10.1016/S0014-3057(99)00258-X

[43] Nagai, N., Matsunobe, T. and Imai, T. (2005) Infrared Analysis of Depth Profiles in UV-Photochemical Degradation of Polymers. Polymer Degradation and Stability, 88, 224-233. http://dx.doi.org/10.1016/j.polymdegradstab.2004.11.001

[44] Silverstein, R.M., Bassler, G.C. and Morrill, T.C. (1981) Spectrometric Identification of Organic Compounds. 4th Edition, John Wiley and Sons, New York. 